\title{
Effect of zinc and phosphorus supply on the activity of carbonic anhydrase and the ultrastructure of chloroplast in sweet corn (Zea mays var. saccharata)
}

\begin{abstract}
Phosphorus (P) and zinc ( $\mathrm{Zn})$ interact with each other and this interaction can affect the yield of corn plants. This study was conducted to examine the effect of different levels of $\mathrm{P}$ and $\mathrm{Zn}$ on the ultrastructure of chloroplast and physiological characteristics of corn plants. Sweet corn was grown in nutrient culture containing all combinations of $\mathrm{P}$ at levels of 0.0 and 80.0 $\mathrm{mg} \mathrm{L}-1$ as KH2PO4 and Zn at levels of 0.0 and $20.0 \mathrm{mg} \mathrm{L}-1$ as ZnSO $4.7 \mathrm{H} 2 \mathrm{O}$ and harvested at 14 and 28 days after transplanting. Phosphorus (P) and zinc ( $\mathrm{Zn}$ ) concentrations in leaves increased with increasing $\mathrm{P}$ and $\mathrm{Zn}$ concentration in nutrient solution. Zinc supply did not affect $\mathrm{P}$ concentration but $\mathrm{Zn}$ concentration reduced with increasing $\mathrm{P}$ supply in nutrient solution at both harvests. The lowest amount of chlorophyll content was recorded in Zn20P0 treatment due to the interaction of $\mathrm{Zn}$ with iron in the growth medium. Carbonic anhydrase activity in leaves was enhanced with increasing $\mathrm{Zn}$ levels and decreased with increasing $\mathrm{P}$ levels at both harvest times. Carbonic anhydrase activity is a better indicator of $\mathrm{Zn}$ nutritional status than $\mathrm{Zn}$ concentration alone. The ultrastructure of chloroplast was affected with $\mathrm{P}$ and Zn supply.
\end{abstract}

Keyword: Carbonic anhydrase; Chloroplast ultrastructure; Phosphorus; Transmission electron microscopy; Zinc 